\title{
Management of critically ill patients with COVID-19: suggestions and instructions from the coordination of intensive care units of Lombardy
}

\author{
Giuseppe FOTI 1, 2, Alberto GIANNINI 3, Nicola BOTTINO 4, \\ Gian Paolo CASTELLI 5, Maurizio CECCONI 6, 7, Giacomo GRASSELLI 4, 8 , \\ Luca GUATTERI ${ }^{9}$, Nicola LATRONICO ${ }^{3,10,11}$, Thomas LANGER ${ }^{2,12}$, Giacomo MONTI 13, \\ Stefano MUTTINI 14, Antonio PESENTI 4, 8, Danilo RADRIZZANI 15, Marco RANUCCI 16, \\ Vincenzo RUSSOTTO 1,2 *, Roberto FUMAGALLI 2, 12, COVID-19 Lombardy ICU Network *
}

${ }^{1}$ Department of Emergency and Intensive Care, San Gerardo University Hospital, Monza, Italy; ${ }^{2}$ School of Medicine and Surgery, University of Milan-Bicocca, Milan, Italy; ${ }^{3}$ Unit of Pediatric Anesthesiology and Intensive Care, Children's Hospital, ASST Spedali Civili Hospital, Brescia, Italy; ${ }^{4}$ Department of Anesthesiology, Reanimation and Emergency, Fondazione IRCCS Ca' Granda Ospedale Maggiore Policlinico, Milan, Italy; ${ }^{5}$ Department of Anesthesiology and Intensive Care, ASST Mantua, Carlo Poma Hospital, Mantua, Italy; ${ }^{\circ}$ Department of Anesthesiology and Intensive Care Medicine, IRCCS Humanitas Clinic, Rozzano, Milan, Italy; ${ }^{7}$ Humanitas University, Pieve Emanuele, Milan, Italy; ${ }^{8}$ Department of Pathophysiology and Transplantation, University of Milan, Milan, Italy; ${ }^{9}$ Department of Anesthesiology and Intensive Care, Sacra Famiglia Fatebenefratelli Hospital, Erba, Como, Italy; ${ }^{10}$ Department of Medical and Surgical Specialties, Radiological Sciences, and Public Health, University of Brescia, Brescia, Italy; ${ }^{11}$ Department of Anesthesiology, Critical Care and Emergency, ASST Spedali Civili, Brescia, Italy; ${ }^{2}$ Department of Anesthesiology and Intensive Care, ASST Grande Ospedale Metropolitano Niguarda, Milan, Italy; ${ }^{13}$ Department of Anesthesiology and Intensive Care, IRCCS San Raffaele Hospital, Milan, Italy; ${ }^{14}$ Department of Anesthesiology and Intensive Care, ASST Santi Paolo e Carlo, San Carlo Hospital, Milan, Italy; ${ }^{15}$ Department of Anesthesiology and Intensive Care, ASST Ovest Milanese, Hospital of Legnano, Legnano, Milan, Italy; ${ }^{16}$ Department of Anesthesiology and Intensive Care, IRCCS San Donato Hospital, Milan, Italy

¥Members are listed at the end of the paper

*Corresponding author: Vincenzo Russotto, Department of Emergency and Intensive Care, San Gerardo University Hospital, Via Pergolesi 33, 20900 Monza, Italy. E-mail: vincenzo.russotto@unimib.it

\section{A B S T R A C T}

With 63,098 confirmed cases on 17 April 2020 and 11,384 deaths, Lombardy has been the most affected region in Italy by coronavirus disease 2019 (COVID-19). To cope with this emergency, the COVID-19 Lombardy intensive care units (ICU) network was created. The network identified the need of defining a list of clinical recommendations to standardize treatment of patients with COVID-19 admitted to Intensive Care Unit (ICU). Three core topics were identified: 1) rational use of intensive care resources; 2) ventilation strategies; 3) non-ventilatory interventions. Identification of patients who may benefit from ICU treatment is challenging. Clinicians should consider baseline performance and frailty status and they should adopt disease-specific staging tools. Continuous positive airway pressure, mainly delivered through a helmet as elective method, should be considered as initial treatment for all patients with respiratory failure associated with COVID-19. In case of persisting dyspnea and/or desaturation despite 4-6 hours of noninvasive ventilation, endotracheal intubation and invasive mechanical ventilation should be considered. In the early phase, muscle relaxant use and volumecontrolled ventilation is recommended. Prone position should be performed in patients with $\mathrm{PaO}_{2} / \mathrm{FiO}_{2} \leq 100 \mathrm{mmHg}$. For patients admitted to ICU with COVID-19 interstitial pneumonia, we do not recommend empiric antibiotic therapy for community-acquired pneumonia. Consultation of an infectious disease specialist is suggested before start of any antiviral therapy. In conclusion, the COVID-19 Lombardy ICU Network identified a list of best practice statements supported by 


\section{COPYRIGHT $^{\odot} 2020$ EDIZIONI MINERVA MEDICA}

MANAGEMENT OF CRITICALLY ILL PATIENTS WITH COVID-19

FOTI

the available evidence and clinical experience or identified as panel members expert opinions for the management of critically ill patients with COVID-19.

(Cite this article as: Foti G, Giannini A, Bottino N, Castelli GP, Cecconi M, Grasselli G, et al. Management of critically ill patients with COVID-19: suggestions and instructions from the coordination of intensive care units of Lombardy. Minerva Anestesiol 2020;86:1234-45. DOI: 10.23736/S0375-9393.20.14762-X)

KEY WORDS: COVID-19; Respiratory distress syndrome, adult; Pandemics.

Q evere acute respiratory syndrome coronavirus $\mathrm{N}_{2}$ (SARS-CoV-2) outbreak represents one of the biggest challenges of modern medicine. The first patient with Coronavirus disease 2019 (COVID-19) in Italy was diagnosed on February 20, 2020 in the region of Lombardy. Since then, we assisted to an dramatic increase of COVID-19 patients in Lombardy, up to a total of 63,098 confirmed cases on April 17 with 11,384 deaths. ${ }^{1}$ A significant proportion of COVID-19 patients (ranging from $5 \%$ to $15 \%$ of the patients needing hospital admission) develop severe respiratory distress syndrome (ARDS) requiring Intensive Care Unit (ICU) admission. To cope with the enormous number of patients needing intensive treatments, a regional network of dedicated COVID-19 ICUs was created and patient allocation was coordinated by a central Taskforce. The COVID-19 Lombardy ICU network includes over 90 units in 72 hospitals of the region, and the total regional ICU bed capacity has been increased from 750 to almost 1800 beds. ${ }^{2,3}$ As of April 22, more than 4,000 critically ill patients have been admitted to one of the ICUs of the Network. More than $80 \%$ of these patients were intubated and on invasive mechanical ventilation at ICU admission. At the same time, a more than double number of patients have been assisted with some form of noninvasive respiratory support (mostly continuous positive airway pressure, CPAP) in the hospital wards, under the direct supervision of intensivists. ${ }^{3}$

In this setting of significant mismatch between the available resources and the request for intensive care, a number of ICUs with limited experience in the treatment of ARDS patients were included in the Regional Network and physicians and nurses from other specialties were directly involved in the care of critically ill patients. Hence, the central coordination taskforce identified the need of defining a list of clinical recommendations in order to standardize patient treatment among the ICUs of the Network. ${ }^{2}$ The aim of these recommendation are: 1) harmonization of interventions among different centers in order to provide the highest level of evidencebased care; 2) provide a practical, bedside tool for those healthcare providers not familiar with the care of severe ARDS patients; 3) limit errors which may increase in stressful environments; 4) support healthcare providers in the identification of the patients who may benefit most from ICU admission and invasive treatments.

\section{Methods}

This statement was planned on March 14, 2020 when we identified the urgent need for a practice guideline for clinicians dealing with COVID-19 critically ill patients. The aim was to identify peculiarities and priorities of their management, based on the evolving experience of the Centers with the highest admission rates in the region of Lombardy, Italy.

During a web-based call, panel members identified three major core topics on management of COVID-19 critically ill patients during the Lombardy outbreak: 1) rational use of intensive care resources; 2) ventilation strategy and prone position; 3) non-ventilatory interventions.

The panel organized three different study groups, each performing a review of available evidence on the above topics.

The following represents the list of best practice statements supported by the available evidence or identified as panel members expert opinions. It should be highlighted that knowledge on COVID-19 has been evolving during these last few weeks, and different proposed interventions, rather than representing translation of evidence from ARDS by other etiologies, result from direct experience of patients' care. 


\section{COPYRIGHT $^{\circledR} 2020$ EDIZIONI MINERVA MEDICA}

FOTI

Finally, we aimed at providing a pragmatic tool which could represent the best integration of potential effective interventions and pandemic reallife, with high workload and limited resources of critical care staff.

\section{Rational use of intensive care resources}

These recommendations may help clinicians dealing with the difficult choices carried by the rapid increase of patients needing critical care support, overwhelming local medical resources as it typically occurs in the setting of disaster medicine. ${ }^{4}$

Clearly, we are not familiar with this kind of situation and it calls for a great effort to cope with the current condition and despite it endeavor to do our best to cope with the emergency and save as many lives as possible.

It must be stressed that one of the most important skills acquired by the intensivist is the identification of patients who can benefit from lifesustaining treatments. This decision is made by identifying those patients with a sufficient level of potential functional recovery for an acceptable quality of life (according to patient's perspective). ${ }^{5}$ It is important to strive to make the right choice to give the greatest possible chances to patients with good physiological reserves, and to avoid unnecessary suffering from intensive and invasive treatments for patients with less hope. ${ }^{6}$
In practice, the first decision, perhaps the most difficult and certainly the most important, is the identification of which patients to treat intensively. This notion of good clinical practice is always important, whether free beds are plentiful or in critical period of beds shortage. ${ }^{7}$

At a time of particularly limited resources such as during a pandemic, these decisions need to be taken with as much care as possible.

Never before the concept of the shortage of available ICU beds materialized. During the last two months the saturation of intensive beds has always exceeded $90 \%$ and during peak pandemic it was above $98 \%$. This demand has been met by continuously adding ICU beds capacity (Figure 1).

We needed to establish criteria to plan in advance the patients for whom admission to ICU and/or continuing intensive care was not proportionate.

Eligibility for critical care treatments should consider the baseline performance and frailty status which should be assessed also by validated tools such as the clinical frailty scale (CFS) $)^{8,9}$ or the palliative performance scale (PPS). ${ }^{10,}{ }^{11}$ Eligibility for critical care resources should not be based solely on patient's age.

- We recommend assessing the baseline functional status using the staging tools specific for each comorbidity (e.g. New York Heart Association classification for heart failure, global initia-

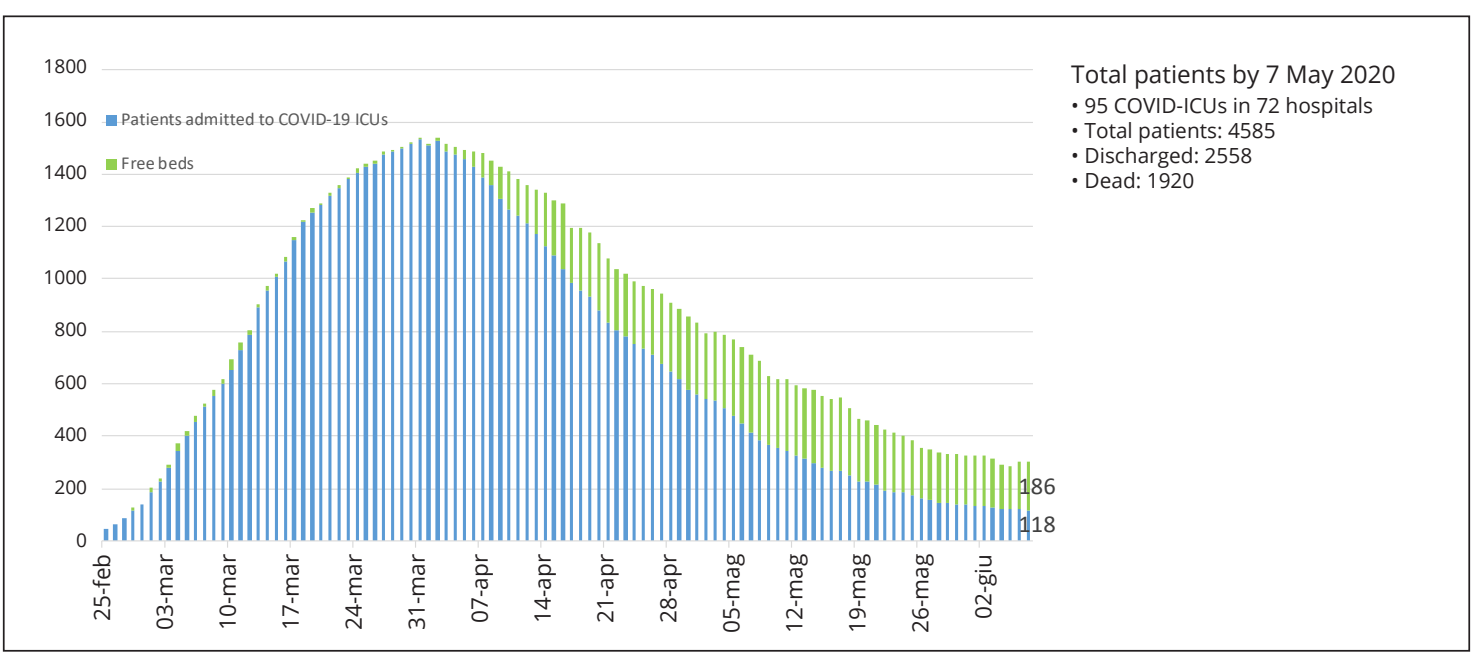

Figure 1.- Trend of patients admitted to the ICUs of the COVID-19 Lombardy Network from 25 February 2020. 


\section{COPYRIGHT $^{\circledR} 2020$ EDIZIONI MINERVA MEDICA}

tive for obstructive lung disease classification, Child-Pugh Classification for chronic liver disease);

- for more complex cases we recommend the second opinion of a colleague for a comprehensive assessment of the clinical condition;

- in case of uncertainties on ICU eligibility, we recommend proceeding to ICU admission providing the highest level of organ support and to proceed with a reassessment of the clinical response after few days (ICU trial). In case of lack of clinical improvement despite maximized care or in case of developing of a new organ failure/ deteriorating clinical condition, we suggest reconsidering the indication to ICU admission and to withdraw intensive care treatments if they are not considered of any further benefit;

- we recommend proceeding by consensus on the decision on either not eligibility to ICU admission or organ support withdrawal. Whenever possible, decisions should be shared with the patient and his/her relatives;

- CPAP delivered through a helmet as elective method, should be considered as initial treatment for all patients with respiratory failure associated with COVID-19;

- CPAP is an effective respiratory support especially for frail patients. Indeed, available data report a mean ICU stay of more than two weeks when treated with invasive mechanical ventilation. Prolonged invasive ventilation may represent a disproportionate and futile treatment for the frail patient;

- CPAP, however, is a limited and time-consuming resource which may reduce care standards of a ward since it requires close monitoring by staff. In this regard its indication should be carefully considered for patients with a limited life-expectancy.

\section{Ventilation strategy and prone position}

The principle of ventilation strategy for patients with ARDS with COVID-19 is early systematic application of the lung protective ventilatory strategy: low tidal volume, medium-high levels of positive end-expiratory pressure (PEEP), prone position. Noninvasive ventilation (i.e. PEEP + pressure support ventilation) may be associated with the so called patient self-inflicted lung injury (P-SILI) given the high tidal volumes and high transpulmonary pressure. ${ }^{12,} 13$ Moreover, high tidal volumes are associated with a high rate of noninvasive ventilation failure. For these reasons, CPAP has been selected as the primary technique to deliver non-invasive support in such patients.

The helmet should be considered the elective interface for CPAP since it provides a more effective patient's isolation and it limits personnel exposure to patient's respiratory droplets. ${ }^{14,15}$

Figure 2 illustrates the proposed ventilation management of COVID-19 patients with ARDS.

\section{Noninvasive ventilation}

We suggest the following strategy: 1) start CPAP in a patient with dyspnea and $\mathrm{SpO}_{2}<95 \%$ under oxygen therapy (i.e. $15 \mathrm{~L} / \mathrm{min} \mathrm{O}_{2}$ with non-rebreather mask); 2) set a PEEP level of $8 \mathrm{cmH}_{2} \mathrm{O}$; 3) set a minimum flow $>50 \mathrm{~L} / \mathrm{min}$ within the helmet; 4) select a continuous flow delivery system (e.g. Venturi); 5) set the maximum $\mathrm{FiO}_{2}$ to $60 \%$ in order to provide an adequate flow humidification and early identify patients with worsening clinical condition requiring endotracheal intubation and invasive mechanical ventilation; 6) in case of persisting dyspnea and/or desaturation despite 4-6 hours of CPAP, we recommend endotracheal intubation and invasive mechanical ventilation.

\section{Endotracheal intubation}

- Endotracheal intubation is considered among the procedures at highest risk for healthcare operators given the potential exposure to aerosols with a high viral load. We recommend limiting the operators in the room to the smallest number required for airway management;

- for patients with ongoing helmet CPAP, we recommend keeping it as preoxygenation method and during rapid sequence induction up to detection of full muscle relaxation since this may limit spreading of patient's droplets. With the help of a second operator, the helmet is then pulled out after gas flow interruption to allow laryngoscopy; 16

- if trained on its use and available, we suggest the use of a videolaryngoscope which may increase first-pass success rate and allow a fur- 


\section{COPYRIGHT $^{\circledR} 2020$ EDIZIONI MINERVA MEDICA}

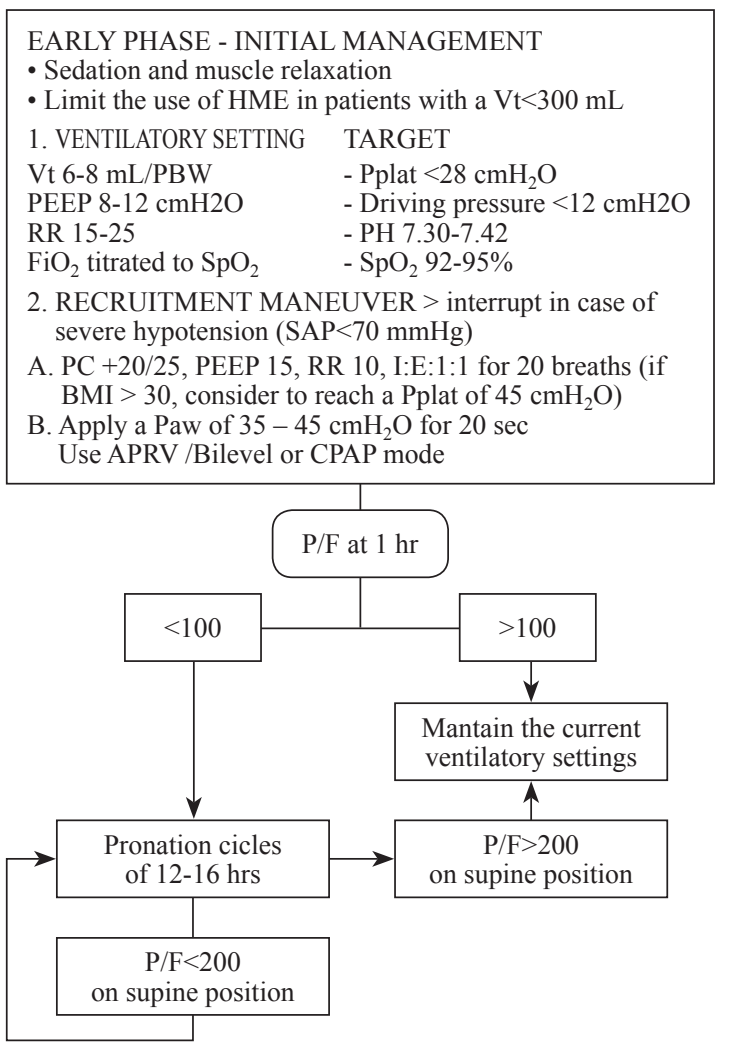

AFTER CLINICAL STABILIZATION TARGET

When $\mathrm{P} / \mathrm{F}>200$ with a $\mathrm{PEEP} \leq 12 \mathrm{cmH}_{2} \mathrm{O}-\mathrm{SpO}_{2} 92-95 \%$ in supine position for at least 12 hours - PH 7.30-7.42

1. Interrupt muscle relaxant

$-\mathrm{P} / \mathrm{F}>200$

2. Titrate sedation (target RASS 0/-1) - FR spont 12-25

3. Attempt spontaneous ventilation

$-\mathrm{P}_{0.1}<3$

$-\mathrm{Vt}$ spont $<6-10 /$

Kg PBW

- Start with PS of 8-10 $\mathrm{cmH}_{2} \mathrm{O}$

- In patients with signs of derecruitment during weaning consider $1 \mathrm{sigh} / \mathrm{min}$ with $\mathrm{P}_{\max } 30-35 \mathrm{cmH}_{2} \mathrm{O}$

In case of failure of spontaneous ventilation

- Patient-ventilator dyssynchronies: optimize ventilation

- Worsening of gas-exchange: (derecruitment or disease progression): switch to controlled ventilation

If $\mathrm{P} / \mathrm{F}>200$ during spontaneous ventilation with adequate thoraco-abdominal coordination, reduce PEEP by $2 \mathrm{cmH} 2 \mathrm{O}$ every $8-12 \mathrm{hrs}$

\section{EXTUBATION}

When PEEP $\leq 6 \mathrm{cmH}_{2} \mathrm{O}, \mathrm{FiO}_{2}<40 \%$, pressure support $<6$, $\mathrm{P} / \mathrm{F}>200$ with adequate thoraco-abdominal coordination > Start CPAP or NPPV after extubation

Figure 2.-Proposed algorithm for ventilatory management of COVID-19 patients with ARDS. ther distance between the operator and patient's airways, especially using those devices with a separate monitor; ${ }^{17}$

- we recommend starting mechanical ventilation only after cuff inflation. We recommend the registration of tube depth and cuff pressure at every shift and before procedures associated with a risk of tube displacement (e.g. oral toilet, prone positioning).

\section{Invasive mechanical ventilation}

- For all patients under invasive mechanical ventilation we recommend the use of a closed suction system; ${ }^{18}$

- we recommend active humidification instead of heat and moisture exchanger (HME) use in patients requiring a tidal ventilation lower than $300 \mathrm{ml}$ in order to limit the dead space volume; 19

- we suggest a muscle relaxant in the early phase of severe hypoxia;20, 21

- we suggest starting with the following ventilation settings:

- volume controlled ventilation with a set tidal volume of 6-8 $\mathrm{mL}$ for predicted body weight, PEEP 8-12 $\mathrm{cmH}_{2} \mathrm{O}$ and respiratory rate 15-25/min. Set $\mathrm{FiO}_{2}$ to address a $\mathrm{SpO}_{2}$ of 92$95 \%$. Titrate respiratory rate to reach a target $\mathrm{PH}$ of 7.30 to 7.42 avoiding hypocapnia;

- a proposed ventilation target could be:

- $\mathrm{SpO}_{2}$ 92-95\%;

- PH 7.30-7.42;

- plateau pressure $<28 \mathrm{cmH}_{2} \mathrm{O}$;

- driving pressure $<12 \mathrm{cmH}_{2} \mathrm{O}$.

\section{Recruitment maneuver}

In case of severe hypoxemia (i.e $\mathrm{PaO}_{2} / \mathrm{FiO}_{2} \leq 100$ ) a recruitment maneuver should be considered if confident with this intervention. The operator performing this maneuver should be aware of the potential hemodynamic impact of it and be ready for its interruption in case of severe hypotension (i.e. systolic arterial pressure $<70 \mathrm{mmHg}$ ). It could be performed using one of the following modalities:

- recruitment modality 1 :

- set the ventilator on pressure-controlled mode;

- set the PEEP level to $15 \mathrm{cmH}_{2} \mathrm{O}$; 


\section{COPYRIGHT $^{\circledR} 2020$ EDIZIONI MINERVA MEDICA}

- set the pressure control to $20-25 \mathrm{cmH}_{2} \mathrm{O}$ above the PEEP level;

- in case of obese patients (i.e. $\mathrm{BMI} \geq 30$ ) consider setting a pressure control level aiming at reaching a plateau pressure of $40 \mathrm{cmH}_{2} \mathrm{O}$;

- set respiratory frequency to $10 / \mathrm{min}$;

- set I:E to $1: 1$;

- keep the previous ventilatory setting for 2 minutes (i.e. 20 breaths) and interrupt it in case of hypotension development.

- Recruitment modality 2:

- apply an airway pressure of 35-40 cm$\mathrm{H}_{2} \mathrm{O}$ for 20 seconds. According to the available ventilator, this goal can be reached using either an airway pressure release ventilation (APRV) mode or CPAP;

- at the end of the recruitment maneuver, set the ventilator as previously suggested.

\section{Prone position}

In case of persisting severe hypoxemia (i.e. $\mathrm{PaO}_{2} /$ $\mathrm{FiO}_{2} \leq 100$ ) despite ventilation optimization, we recommend prone position. ${ }^{22}$

We suggest performing pronation in trained centers since this maneuver may carry a high risk in case of limited resources or not expert personnel.

\section{Spontaneous ventilation}

- When a patient improves his/her oxygenation with a $\mathrm{PaO}_{2} / \mathrm{FiO}_{2}>200$ with a PEEP $\leq 12$ $\mathrm{cmH}_{2} \mathrm{O}$ in supine position for at least 12 hours and 3-5 days of controlled ventilation, we suggest to interrupt muscle relaxant use, target sedation to Richmond agitation-sedation Scale (RASS) 0/-1 and attempt assisted ventilation;

- we suggest setting the ventilator to synchronized intermittent mandatory ventilation (SIMV) mode, with a progressive reduction of mandatory respiratory breaths;

- we suggest an initial pressure support level of $8-12 \mathrm{cmH}_{2} \mathrm{O}$. In selected patients with signs of derecruitment during the weaning process, a sigh may be considered (e.g. by keeping a single mandatory breath per minute, with a maximum inspiratory pressure, $\mathrm{P}_{\max }$ of $35 \mathrm{cmH}_{2} \mathrm{O}$ and an inspiratory time $\mathrm{T}_{\mathrm{i}}$ of $3-5$ seconds);

- we recommend monitoring tidal volumes during pressure support ventilation. In case of development of high tidal volumes (i.e. $\geq 10 \mathrm{ml} /$ $\mathrm{Kg}$ ) despite ventilatory setting and sedation optimization and temperature control, we recommend switching to controlled ventilation;

- assessment of airway occlusion pressure at 100 milliseconds (P0.1) may be of help in identifying patients with a high respiratory drive.

\section{Weaning}

When a patient maintains a $\mathrm{PaO}_{2} / \mathrm{FiO}_{2}>200$ during assisted ventilation, with an adequate thoraco-abdominal coordination, proceed with a PEEP reduction of $2 \mathrm{cmH}_{2} \mathrm{O}$ every 8-12 hours. When $\mathrm{PEEP} \leq 6 \mathrm{cmH}_{2} \mathrm{O}, \mathrm{FiO}_{2}<40 \%$ and pressure support $\leq 6 \mathrm{cmH}_{2} \mathrm{O}$ is well tolerated for at least 8-12 hours, patient's extubation should be considered.

A session of CPAP or noninvasive positive pressure ventilation after extubation is suggested. ${ }^{23}$

To date more detailed information on the best weaning strategy and on tracheostomy timing are lacking for COVID-19 patients.

\section{Non-ventilatory interventions}

\section{Antibiotic therapy}

For patients admitted to ICU with COVID-19 interstitial pneumonia, we do not recommend empiric antibiotic therapy for community-acquired pneumonia. We suggest interruption of empiric therapy eventually started before ICU admission, with the exception of patients with signs of bacterial infection (e.g. purulent respiratory secretions, high procalcitonin [PCT]). Routine use of empiric antibiotic therapy may, indeed, increase multidrug resistant (MDR) pathogens which may represent a further challenge to current clinical and organizational management (e.g. adoption of contact isolation in addition to personal protective equipment).

Patients with COVID-19 pneumonia present with low levels PCT and this marker may be used for detection and monitoring of bacterial superinfection. ${ }^{24,25}$

We recommend collection of both admission and surveillance culture specimens:

- on admission: urinary antigen test for Legio- 


\section{COPYRIGHT $^{\circledR} 2020$ EDIZIONI MINERVA MEDICA}

nella and Streptococcus pneumoniae and bronchial aspirate culture;

- in case of clinical suspicion, serological screening assay/polymerase chain reaction for specific pathogens should be considered;

- surveillance: bronchial aspirate culture (at least once/week) and rectal swab for identification of patients colonized by multidrug resistant species (e.g. KPC, Acinetobacter baumannii).

In case of positive cultures or increased PCT levels, we recommend use of empiric antibiotic therapy.

\section{Antiviral therapy}

We recommend the consultation of an infectious disease specialist before start of antiviral therapy (including hydroxychloroquine). To date, no clear evidence of efficacy is available. ${ }^{26}$

Different antiviral agents showed an interaction with commonly used drugs in ICU. We recommend referring to the technical information of each drug or to an infectious disease specialist.

\section{Steroids}

Use of steroids is debated. After a first period of active viral replication, different patients show a hyperinflammatory status. In these cases, after bacterial or fungal infections have been ruled out, use of steroids may be considered. ${ }^{27}$

\section{Adjuntive therapies}

Treatments such as tocilizumab (an anti-IL-6 receptor), anakinra (an anti-IL-1 receptor), plasma transfusion of convalescent COVID-19 patients, prone position in non-intubated patients are considered experimental. No recommendations or suggestions can be provided, and every center is free to implement them according to their local experience.

\section{Sedation and neuromuscular block}

- Benzodiazepines should be avoided in COVID-19 patients, especially in those under lopinavir/ritonavir treatment since its use is associated with an unpredictable modification of their pharmacokinetic and pharmacodynamic profiles;

- fentanyl should be administered with caution due to the potential alteration of its prop- erties when associated with lopinavir/ritonavir treatment.

- quetiapine should be avoided due to unfavorable interaction with lopinavir/ritonavir;

- shortage of first line sedatives agents (e.g. propofol) and neuromuscular blocking agents has been reported in several centers. Each center should plan alternative (second-line) strategies for sedation such as enteral agents use, halogenates, long-acting benzodiazepines;

- we highlight the importance of titrated sedatives administration to a sedation goal, preferably with the aid of monitoring systems for sedation depth (e.g. bispectral index, BIS, entropy or other systems). ${ }^{28,29}$ In alternative, daily sedation holds may be implemented;

- we emphasize the importance of adequate titration of neuromuscular blocking agents in order to avoid delays during the weaning process and prolonged mechanical ventilation. This is of utmost importance during this period of ICU beds shortage; 30

- we also suggest that patients with prolonged mechanical ventilation and use of sedatives and neuromuscular blocking agents are followed-up after the acute stage of disease, in order to evaluate physical and mental impairments of this not well-known disease with possible unexpected evolution.

\section{Nutrition}

Both SARS-CoV2 and some antiviral agents (e.g. Lopinavir/Ritonavir) may induce diarrhea. However, in most COVID-19 patients we did not observe gastrointestinal failure. ${ }^{31}$

We suggest early enteral nutrition to be delivered during both supine and prone positions. Mild anti-Trendelenburg Position during prone position may be of help to enhance enteral tolerance.

We recommend starting with $20 \mathrm{~mL} / \mathrm{h}$ and then to increase nutritional support up to 40-60 $\mathrm{mL} / \mathrm{h}$ via enteral route by the first 24 hours and after progressively increase to a maximum of 25 $\mathrm{kcal} / \mathrm{kg}$ by the first week.

\section{Fluid therapy}

COVID-19 patients are hypovolemic at ICU admission as the consequence of fever, reduced flu- 


\section{COPYRIGHT $^{\circledR} 2020$ EDIZIONI MINERVA MEDICA}

id input and fasting. It should be also considered a proportion of relative hypovolemia associated with the high inspiratory pressure of mechanical ventilation in a relatively normally compliant lung with transmission of delivered pressure on cardiovascular system.

We did not observe renal failure in most patients on ICU admission and balanced fluids (e.g. ringer lactate) should be administered with the goal of urine output $>0.5 \mathrm{~mL} / \mathrm{kg}$ and lactate level $<2 \mathrm{mmol} / \mathrm{L}$. During the first 48 hours from ICU admission, a positive fluid balance is unavoidable to reach perfusion targets and administration of diuretics may be detrimental (e.g. renal failure development, electrolytes abnormalities). During the following days of ICU stay, with a more stable clinical condition and ventilation weaning, a negative fluid balance should be considered. ${ }^{32}$

\section{Vasopressor and antiarrhythmic agents}

The elective vasopressor to treat vasodilation associated to sedatives or to other reasons is noradrenaline. ${ }^{33}$ We suggest starting with a low dose of $0.05-0.1 \mathrm{mcg} / \mathrm{kg} / \mathrm{min}$ with a target mean arterial pressure (MAP) $>65 \mathrm{mmHg}$. Consider a higher target for patients with a past history of arterial hypertension. 34,35

In case of new onset or chronic atrial fibrillation we recommend against the use of amiodarone since it may lead to severe arrhythmias when associated with Lopinavir/Ritonavir and hydroxychloroquine. ${ }^{36}$

\section{Antithrombotic prophylaxis}

A growing body of data highlight a higher risk of thromboembolic events in COVID-19 critically ill patients. We recommend to focus on this potential complication, looking for deep vein thrombosis with an aggressive treatment in case of their detection. ${ }^{37-39}$

In different centers a higher target for thromboprophylaxis has been adopted based on D-dimer monitoring:

- in case of D-dimers $<5000 \mathrm{ng} / \mathrm{mL}$ full prophylactic dosage (e.g. enoxaparin $100 \mathrm{UI} / \mathrm{kg}$ subcutaneous injection x 1/day);

- in case of D-dimers $>5000 \mathrm{ng} / \mathrm{mL}$ therapeutic dosage (e.g. enoxaparin $100 \mathrm{UI} / \mathrm{kg}$ subcutaneous injection x 2 /day);
- renal adjustment for glomerular filtration rate $<30 \mathrm{~mL} / \mathrm{min}$.

Different ongoing studies will elucidate the underlying pathophysiologic mechanisms of this observed events, providing more information on therapeutic goals.

\section{Discussion}

This document describes the best statements recommendations for the management of critically ill patients with COVID-19 from the Lombardy ICU Network. To our knowledge this is the first consensus document from an Italian ICU Network.

The aim of this document was to provide a list of pragmatic interventions to support clinicians facing the COVID-19 outbreak.

CPAP was the first respiratory support we delivered to almost all patients with respiratory failure. We suggested the elective adoption of helmet CPAP given its advantages of patient's isolation and limitation of droplets dispersion. Facemask may be considered in case of helmet unavailability or clinicians' preference.

COVID-19 patients may present with high fever and respiratory drive. High minute ventilation and inspiratory effort may be the ground for self-inflicted lung injury and their identification, in non-intubated patients (e.g. on CPAP), relies on the clinical observation in the daily practice. In patients on invasive mechanical ventilation, assessment of airway occlusion pressure at 100 milliseconds (P0.1) may be of help in identifying patients with a high respiratory drive.

Lung-protective ventilation is still the paradigm of COVID-19 ARDS. The notion of ARDS heterogeneity also applies to COVID-19 patients, with apparently different features of lung mechanics observed among patients admitted during these last months. We suggested to apply an initial PEEP level of 8-12 $\mathrm{cmH}_{2} \mathrm{O}$. However, as for general ARDS management, PEEP selection should be individualized given the potential benefit of higher PEEP level in some patients and the lack of benefit of higher PEEP levels in other patients whose hypoxemia may be explained by underlying vascular derangement (e.g. pulmonary vascular emboli or 


\section{COPYRIGHT $^{\circledR} 2020$ EDIZIONI MINERVA MEDICA}

thrombi) ${ }^{40}$ During the course of the pandemic, clinicians caring COVID-19 patients with ARDS reduced the level of applied PEEP with a median level of $14 \mathrm{cmH}_{2} \mathrm{O}$ (interquartile range 12.0-16.0 $\mathrm{cmH}_{2} \mathrm{O}$ ) during the first four weeks in the overall cohort of patients admitted to the Lombardy ICU Network, and a median PEEP of $10 \mathrm{cmH}_{2} \mathrm{O}$ (interquartile range 8.0-12.0) during the last four weeks (unpublished data from the Lombardy ICU Network).

In our non-ventilatory interventions section, we referenced the drugs which, at the time of the consensus, were under investigation and gathered the attention of clinicians, scientific community and public opinion. To date, no high-quality evidence supports antivirals or adjunctive therapies for COVID-19. The path of hydroxychloroquine investigation for COVID-19 is paradigmatic of the challenges posed by the urgent need of effective treatments and development of high-quality evidence. ${ }^{41-43}$

Despite the initial enthusiasm, no evidence to date supports the use of chloroquine/hydroxychloroquine in COVID-19 critically ill patients. ${ }^{44}$

\section{Limitations of the study}

These best practice statements were formulated at the early stage of COVID-19 surge in Lombardy. Given this circumstance, most suggested interventions are the result of direct experience as clinicians and lack high-quality evidence. Nevertheless, given the amount of admitted patients over a short timeframe, we could provide the first clinical useful insights and most suggestions are still relevant also in the light of the currently available higher quality evidence.

\section{Conclusions}

The COVID-19 Lombardy ICU Network identified a list of best practice statements supported by the available evidence and clinical experience or identified as panel members' expert opinions for the management of critically ill patients with COVID-19 with ARDS. Three core topics were identified: use of intensive care resources, ventilation strategies and non-ventilatory interventions.

\section{Key messages}

- Identification of COVID-19 patients who may benefit most from ICU admission is challenging and should consider baseline performance, frailty status and disease-specific staging tools for comorbidities.

- Continuous positive airway pressure has a major role for initial ventilatory management of ARDS in COVID-19 in the condition of ICU bed unavailability.

- Lung-protective ventilation is still the paradigm of treatment. More severe cases on invasive ventilation may benefit from prone positioning.

- Non-ventilatory management includes careful administration of steroids, titration of sedation level to enhance weaning, surveillance on bacterial infections and thromboembolic complications.

\section{References}

1. Istituto Superiore di Sanità. Epidemia COVID-19. Aggiornamento Nazionale. ISS; 2020 [Internet]. Available from: Www.epicentro.iss.it/coronavirus/ [cited 2020, Apr 20].

2. Grasselli G, Pesenti A, Cecconi M. Critical Care Utilization for the COVID-19 Outbreak in Lombardy, Italy: Early Experience and Forecast During an Emergency Response. JAMA 2020;323:1545-6.

3. Grasselli G, Zangrillo A, Zanella A, Antonelli M, Cabrini L, Castelli A, et al.; COVID-19 Lombardy ICU Network. Baseline Characteristics and Outcomes of 1591 Patients Infected With SARS-CoV-2 Admitted to ICUs of the Lombardy Region, Italy. JAMA 2020;323:1574-81.

4. Sever MS, Remuzzi G, Vanholder R. Disaster medicine and response: optimizing life-saving potential. Am J Disaster Med 2018;13:253-64.

5. Raccomandazioni di etica clinica per l'ammissione a trattamenti intensivi e per la loro sospensione, in condizioni eccezionali di squilibrio tra necessità e risorse disponibili. SIAARTI; 2020 [Internet]. Available from: https://www.siaarti.it/SiteAssets/News/COVID19\%20-\%20documenti\%20 SIAARTI/SIAARTI $\% 20-\% 20$ Covid $19 \% 20-\% 20$ Raccomandazioni\%20di\%20etica\%20clinica.pdf [cited 2020, May 5].

6. Cortegiani A, Russotto V, Raineri SM, Gregoretti C, Giarratano A, Mercadante S. Attitudes towards end-oflife issues in intensive care unit among Italian anesthesiologists: a nation-wide survey. Support Care Cancer 2018;26:1773-80.

7. Lobo SM, De Simoni FH, Jakob SM, Estella A, Vadi S, Bluethgen A, et al.; ICON investigators. Decision-Making on Withholding or Withdrawing Life Support in the ICU: A Worldwide Perspective. Chest 2017;152:321-9.

8. Reichart D, Rosato S, Nammas W, Onorati F, Dalén $\mathrm{M}$, Castro L, et al. Clinical frailty scale and outcome after 


\section{COPYRIGHT $^{(} 2020$ EDIZIONI MINERVA MEDICA}

coronary artery bypass grafting. Eur J Cardiothorac Surg 2018;54:1102-9.

9. Muessig JM, Nia AM, Masyuk M, Lauten A, Sacher AL, Brenner T, et al. Clinical Frailty Scale (CFS) reliably stratifies octogenarians in German ICUs: a multicentre prospective cohort study. BMC Geriatr 2018;18:162-9.

10. Anderson F, Downing GM, Hill J, Casorso L, Lerch N. Palliative performance scale (PPS): a new tool. J Palliat Care 1996;12:5-11.

11. Ho F, Lau F, Downing MG, Lesperance M. A reliability and validity study of the Palliative Performance Scale. BMC Palliat Care 2008;7:10-10.

12. Gattinoni L, Chiumello D, Caironi P, Busana M, Romitti F, Brazzi L, et al. COVID-19 pneumonia: different respiratory treatments for different phenotypes? Intensive Care Med 2020;46:1099-102.

13. Russotto V, Bellani G, Foti G. Respiratory mechanics in patients with acute respiratory distress syndrome. Ann Transl Med 2018;6:382-382.

14. Patel BK, Wolfe KS, Pohlman AS, Hall JB, Kress JP. Effect of Noninvasive Ventilation Delivered by Helmet vs Face Mask on the Rate of Endotracheal Intubation in Patients With Acute Respiratory Distress Syndrome: A Randomized Clinical Trial. JAMA 2016;315:2435-41.

15. Lucchini A, Giani M, Isgrò S, Rona R, Foti G. The "helmet bundle" in COVID-19 patients undergoing non invasive ventilation. Intensive Crit Care Nurs 2020;58:102859.

16. Russotto V, Cortegiani A, Raineri SM, Gregoretti C, Giarratano A. Respiratory support techniques to avoid desaturation in critically ill patients requiring endotracheal intubation: A systematic review and meta-analysis. J Crit Care 2017;41:98-106.

17. Russotto V, Myatra SN, Laffey JG. What's new in airway management of the critically ill. Intensive Care Med 2019;45:1615-8.

18. Pedersen CM, Rosendahl-Nielsen M, Hjermind J, Egerod I. Endotracheal suctioning of the adult intubated patient-what is the evidence? Intensive Crit Care Nurs 2009;25:21-30.

19. Morán I, Bellapart J, Vari A, Mancebo J. Heat and moisture exchangers and heated humidifiers in acute lung injury/ acute respiratory distress syndrome patients. Effects on respiratory mechanics and gas exchange. Intensive Care Med 2006;32:524-31.

20. Papazian L, Forel JM, Gacouin A, Penot-Ragon C, Perrin G, Loundou A, et al.; ACURASYS Study Investigators. Neuromuscular blockers in early acute respiratory distress syndrome. N Engl J Med 2010;363:1107-16.

21. Moss M, Huang DT, Brower RG, Ferguson ND, Ginde AA, Gong MN, et al.; National Heart, Lung, and Blood Institute PETAL Clinical Trials Network. Early Neuromuscular Blockade in the Acute Respiratory Distress Syndrome. N Engl J Med 2019;380:1997-2008.

22. Guérin C, Reignier J, Richard JC, Beuret P, Gacouin A, Boulain T, et al.; PROSEVA Study Group. Prone positioning in severe acute respiratory distress syndrome. N Engl J Med 2013;368:2159-68.

23. Kacmarek RM. Noninvasive Respiratory Support for Postextubation Respiratory Failure. Respir Care 2019;64:658-78.

24. Huang DT, Yealy DM, Filbin MR, Brown AM, Chang $\mathrm{CH}$, Doi Y, et al.; ProACT Investigators. Procalcitonin-Guided Use of Antibiotics for Lower Respiratory Tract Infection. N Engl J Med 2018;379:236-49.

25. Schuetz P, Wirz Y, Mueller B. Procalcitonin Testing to
Guide Antibiotic Therapy in Acute Upper and Lower Respiratory Tract Infections. JAMA 2018;319:925-6.

26. Cao B, Wang Y, Wen D, Liu W, Wang J, Fan G, et al. A Trial of Lopinavir-Ritonavir in Adults Hospitalized with Severe Covid-19. N Engl J Med 2020;382:1787-99.

27. Ritchie AI, Singanayagam A. Immunosuppression for hyperinflammation in COVID-19: a double-edged sword? Lancet 2020;395:1111.

28. Shetty RM, Bellini A, Wijayatilake DS, Hamilton MA, Jain R, Karanth S, et al. BIS monitoring versus clinical assessment for sedation in mechanically ventilated adults in the intensive care unit and its impact on clinical outcomes and resource utilization. Cochrane Database Syst Rey 2018;2:CD011240.

29. Mondello E, Siliotti R, Noto G, Cuzzocrea E, Scollo G, Trimarchi G, et al. Bispectral Index in ICU: correlation with Ramsay Score on assessment of sedation level. J Clin Monit Comput 2002;17:271-7.

30. Mehta S, Burry L, Cook D, Fergusson D, Steinberg M, Granton J, et al.; SLEAP Investigators; Canadian Critical Care Trials Group. Daily sedation interruption in mechanically ventilated critically ill patients cared for with a sedation protocol: a randomized controlled trial. JAMA 2012;308:1985-92.

31. Pironi L, Corcos O, Forbes A, Holst M, Joly F, Jonkers $\mathrm{C}$, et al.; ESPEN Acute and Chronic Intestinal Failure Special Interest Groups. Intestinal failure in adults: recommendations from the ESPEN expert groups. Clin Nutr 2018;37(6 Pt A):1798-809.

32. Wiedemann HP, Wheeler AP, Bernard GR, Thompson BT, Hayden D, deBoisblanc B, et al.; National Heart, Lung, and Blood Institute Acute Respiratory Distress Syndrome (ARDS) Clinical Trials Network. Comparison of two fluidmanagement strategies in acute lung injury. N Engl J Med 2006;354:2564-75.

33. Alhazzani W, Møller MH, Arabi YM, Loeb M, Gong MN, Fan E, et al. Surviving Sepsis Campaign: guidelines on the management of critically ill adults with Coronavirus Disease 2019 (COVID-19). Intensive Care Med 2020;46:854-87.

34. Asfar P, Meziani F, Hamel JF, Grelon F, Megarbane B, Anguel N, et al.; SEPSISPAM Investigators. High versus low blood-pressure target in patients with septic shock. N Engl J Med 2014;370:1583-93.

35. Beloncle F, Radermacher $P$, Guérin $C$, Asfar P. Mean arterial pressure target in patients with septic shock. Minerva Anestesiol 2016;82:777-84.

36. Gori T, Lelieveld J, Münzel T. Perspective: cardiovascular disease and the Covid-19 pandemic. Basic Res Cardiol 2020;115:32.

37. Klok FA, Kruip MJ, van der Meer NJ, Arbous MS, Gommers DA, Kant KM, et al. Incidence of thrombotic complications in critically ill ICU patients with COVID-19. Thromb Res 2020;191:145-7.

38. Panigada M, Bottino N, Tagliabue P, Grasselli G, Novembrino $\mathrm{C}$, Chantarangkul V, et al. Hypercoagulability of COVID-19 patients in intensive care unit: A report of thromboelastography findings and other parameters of hemostasis. J Thromb Haemost 2020;18:1738-42.

39. Ranucci M, Ballotta A, Di Dedda U, Bayshnikova E, Dei Poli M, Resta M, et al. The procoagulant pattern of patients with COVID-19 acute respiratory distress syndrome. J Thromb Haemost 2020;18:1747-51.

40. Fan E, Beitler JR, Brochard L, Calfee CS, Ferguson ND, Slutsky AS, et al. COVID-19-associated acute respiratory distress syndrome: is a different approach to management warranted? Lancet Respir Med 2020;8:816-21.

41. Citerio G, Bakker J, Brochard L, Buchman TG, Jaber 


\section{COPYRIGHT $^{(} 2020$ EDIZIONI MINERVA MEDICA}

$\mathrm{S}$, Mazzone PJ, et al. Critical care journals during the COVID-19 pandemic: challenges and responsibilities. Intensive Care Med 2020;46:1521-3.

42. Mahase E. Hydroxychloroquine for covid-19: the end of the line? BMJ 2020;369:m2378.

43. Taccone FS, Gorham J, Vincent JL. Hydroxychloroquine in the management of critically ill patients with CO-
VID-19: the need for an evidence base. Lancet Respir Med 2020;8:539-41.

44. Rosenberg ES, Dufort EM, Udo T, Wilberschied LA, Kumar J, Tesoriero J, et al. Association of Treatment With Hydroxychloroquine or Azithromycin With In-Hospital Mortality in Patients With COVID-19 in New York State. JAMA 2020;323:2493-502.

Conflicts of interest.-Giuseppe Foti received speaker and consultancy honoraria by Dimar and Intersurgical; Maurizio Cecconi received speaker and consultancy honoraria by Edwards Lifesciences, Directed Systems, Cheetah Medical; Giacomo Grasselli received speaker/congress participation honoraria by Maquet, Pfizer, Draeger, Thermofisher, MSD, Biotest; Antonio Pesenti received honoraria for lectures and scientific boards participation by Maquet, Baxter, Xenios. All other authors declare no conflict of interests for this manuscript. The authors certify that there is no conflict of interest with any financial organization regarding the material discussed in the manuscript.

Group name.--Emiliano AGOSTEO (San Carlo Clinical Institute, Milan, Italy); Valentina ALAIMO (ASST Mantua, Carlo Poma Hospital, Mantua, Italy); Giovanni ALBANO (Humanitas Gavazzeni Hospital, Bergamo, Italy); Andrea ALBERTIN (San Giuseppe Hospital, Milan, Italy); Armando ALBORGHETTI (Policlinico San Pietro, Ponte San Pietro, Bergamo, Italy); Giorgio ALDEGHERI (IRCCS Multimedica, Sesto San Giovanni, Milan, Italy); Benvenuto ANTONINI (ASST Garda, Hospital of Manerbio, Manerbio. Brescia, Italy); Enrico BARBARA (Humanitas Mater Domini Hospital, Castellanza, Varese, Italy); Nicolangela BELGIORNO (San Rocco Institute, Ome, Brescia, Italy); Mirko BELLIATO (Department of Clinical Surgery, Pediatric and Diagnostic Sciences, University of Pavia, Pavia, Italy); Annalisa BENINI (ASST Monza, San Gerardo Hospital, Monza, Italy); Enrico BERETTA (ATS Montagna, Eugenio Morelli Hospital, Sondalo, Sondrio, Italy); Leonardo BIANCIARDI (ASST Mantua, Hospital of Pieve di Coriano, Mantua, Italy); Stefano BONAZZI (ASST Bergamo Est, A. Locatelli Hospital, Bergamo, Italy); Massimo BORELLI (TreviglioCaravaggio Hospital, Treviglio, Bergamo, Italy); Enrico BOSELLI (ASST Rhodense, Hospital of Garbagnate Milanese, Milan, Ita1y); Nicola BRONZINI (Sant'Anna Institute, Brescia, Italy); Luca CABRINI (ASST Laghi, Circolo e Fondazione Macchi Hospital, Varese, Italy); Carlo CAPRA (ASST Laghi, Circolo e Fondazione Macchi Hospital, Varese, Italy); Livio CARNEVALE (ASST Pavia, Hospital of Vigevano, Vigevano, Italy); Giampaolo CASELLA (ASST Grande Ospedale Metropolitano Niguarda, Milan, Italy); Antonio CASTELLI (ASST Fatebenefratelli Sacco, Luigi Sacco Hospital, University of Milan, Milan, Italy); Gianpaolo CASTELLI (ASST Mantua, Carlo Poma Hospital, Mantua, Italy); Emanuele CATENA (ASST Fatebenefratelli Sacco, Luigi Sacco Hospital, University of Milan, Milan, Italy); Sergio CATTANEO (ASST Spedali Civili, Brescia, Italy); Maurizio CECCONI (Humanitas University, Pieve Emanuele, Milan, Italy); Davide CHIUMELLO (ASST Santi Paolo e Carlo, San Paolo Hospital, Milan, Italy); Silvia CIRRI (Sant'Ambrogio Institute, Milan, Italy); Giuseppe CITERIO (ASST Monza, Desio Hospital, Monza, Italy); Sergio COLOMBO (IRCCS San Raffaele Hospital, Vita-Salute San Raffaele University, Milan, Italy); Antonio COLUCCELLO (ASST Cremona, Hospital of Cremona, Cremona, Italy); Davide COPPINI (ASST Garda, La Memoria Hospital, Gavardo, Italy); Alberto CORONA (ASST Vallecamonica, Hospital of Valle Camonica Esine, Brescia, Italy); Paolo CORTELLAZZI (ASST Nord Milan, Sesto San Giovanni Hospital, Milan, Italy); Elena COSTANTINI (Humanitas University, Pieve Emanuele, Milan, Italy); Remo Daniel COVELLO (ASST Valle Olona, Hospital of Busto Arsizio, Busto Arsizio, Italy); Gianluca DE FILIPPI (ASST Rhodense, Hospital of Garbagnate Milanese, Garbagnate Milanese, Milan, Italy); Marco DEI POLI (IRCCS San Donato Hospital, Milan, Italy); Federica DELLA MURA (ASST Melegnano, Vizzolo Predabissi Hospital, Melegnano, Milan, Italy); Giulia EVASI (ASST Lecco, Lecco Hospital, Lecco, Italy); Raquel FERNANDEZ-OLMOS (Fondazione Poliambulanza Hospital, Brescia, Italy); Andrea FORASTIERI MOLINARI (ASST Lecco, Hospital of Lecco, Lecco, Italy); Giuseppe FOTI (Department of Emergency and Intensive Care, San Gerardo University Hospital, Monza, Italy); Roberto FUMAGALLI (ASST Grande Ospedale Metropolitano Niguarda, Milan, Italy); Marco GALLETTI (Valduce Hospital, Como, Italy); Giorgio GALLIOLI (ASST Vimercate, Hospital of Vimercate, Vimercate, Monza-Brianza, Italy); Marco GEMMA (ASST Fatebenefratelli Sacco, Luigi Sacco Hospital, University of Milan, Milan, Italy); Paolo GNESIN (ASST Franciacorta, Mellino Mellini Hospital, Chiari, Brescia, Italy); Giacomo GRASSELLI (Fondazione IRCCS Ca' Granda Ospedale Maggiore Policlinico, Milan, Italy); Lorenzo GRAZIOLI (ASST Papa Giovanni XXIII, Bergamo, Italy); Stefano GRECO (ASST Valle Olona, Hospital of Saronno, Saronno, Varese, Italy); Paolo GRITTI (ASST Papa Giovanni XXIII, Bergamo, Italy); Paolo GROSSO (Monza Polyclinic, Monza, Italy); Luca GUATTERI (Sacra Famiglia Fatebenefratelli Hospital, Erba, Como, Italy); Davide GUZZON (ASST Lecco, Hospital of Merate, Merate, Lecco, Italy); Fabiola HARIZAY (ASST Cremona, Hospital of Cremona, Cremona, Italy); Giorgio IOTTI (IRCCS San Matteo Polyclinic, Pavia, Italy); Roberto KEIM (ASST Bergamo Est, Bolognini Hospital, Seriate, Bergamo, Italy); Giovanni LANDONI (IRCCS Ospedale San Raffaele Scientific Institute, Milan, Italy); Thomas LANGER (ASST Grande Ospedale Metropolitano Niguarda, Milan, Italy); Nicola LATRONICO (ASST Spedali Civili, Brescia, Italy); Andrea LOMBARDO (ASST Lariana, Sant'Anna Hospital, Como, Italy); Ferdinando L. LORINI (ASST Papa Giovanni XXIII, Bergamo, Italy); Annalisa MALARA (ASST Lodi, Maggiore Hospital, Lodi, Italy); Elena MALPETTI (Fondazione Poliambulanza Hospital, Brescia, Italy); Francesco MARINO (Beato Matteo Institute, Vigevano, Pavia, Italy); Giovanni MARINO (ASST Melegnano, Vizzolo Predabissi Hospital, Melegnano, Milan, Italy); Maurizio G. MAZZONI (Humanitas Gavazzeni Hospital, Bergamo, Italy); Guido MERLI (ASST Crema, Maggiore Hospital, Crema, Italy); Antonio MICUCCI (ASST Lariana, Sant'Antonio Abate Hospital, Como, Italy); Francesco MOJOLI (Department of Clinical Surgical, Pediatric and Diagnostic Sciences, University of Pavia, Pavia, Italy); Stefano MUTTINI (ASST Santi Paolo e Carlo, San Carlo Hospital, Milan, Italy); Adriana NAILESCU (ASST Lodi, Maggiore Hospital, Lodi, Italy); Giuseppe NATALINI (Fondazione Poliambulanza Hospital, Brescia, Italy); Mauro PANIGADA (Fondazione IRCCS Ca' Granda Ospedale Maggiore Policlinico, Milan, Italy); Paolo PERAZZO (IRCCS Galeazzi Orthopedic Institute, Milan, Italy); Giovanni B. PEREGO (San Luca Institute, Milan, Italy); Antonio PESENTI (Fondazione IRCCS Ca' Granda Ospedale Maggiore Policlinico, Milan, Italy); Nicola PETRUCCI (ASST Garda, Hospital of Desenzano del Garda, Desenzano del Garda, Brescia, Italy); Angelo PEZZI (ASST Nord Milan, Edoardo Bassini Hospital, Cinisello Balsamo, Milan, Italy); Alessandro PROTTI (Humanitas University, Pieve Emanuele, Milan, Italy); Danilo RADRIZZANI (ASST Ovest Milanese, Hospital of Legnano, Legnano, Milan, Italy); Maurizio RAIMONDI (ASST Pavia, Hospital of Voghera, Voghera, Pavia, Italy); Marco RANUCCI (IRCCS San Donato Hospital, Milan, Italy); Frank RASULO (ASST Spedali Civili, Brescia, Italy); Mario RICCIO (Oglio Po Hospital, Casalmaggiore, Cremona, Italy); Roberto RONA (ASST Monza, San Gerardo Hospital, Monza-Brianza, Italy); Claudio ROSCITANO (Humanitas Gavazzeni Hospital, Bergamo, Italy); Patrizia RUGGERI (ASST Cremona, Hospital of Cremona, Cremona, Italy); Antonello SALA (ASST Vimercate, Hospital of Vimercate, Vimercate, Monza-Brianza, Italy); Giuseppe SALA (Città Studi Institute, Milan, Italy); Luca SALVI (IRCCS Centro Cardiologico Monzino, Milan, Italy); Anna M. SCANDROGLIO (IRCCS 


\section{COPYRIGHT $^{\odot} 2020$ EDIZIONI MINERVA MEDICA}

San Raffaele Hospital, Vita-Salute San Raffaele University, Milan, Italy); Pietro SEBASTIANO (Città di Brescia Institute, San Donato Group, Brescia, Italy); Paolo SEVERGNINI (ASST Sette Laghi, Circolo e Fondazione Macchi Hospital, Varese, Italy); Ilaria SFORZINI (ASST Pavia, Hospital of Voghera, Voghera, Italy); Francesco D. SIGURT (Città di Pavia Institute, Pavia, Italy); Enrico STORTI (ASST Lodi, Maggiore Hospital, Lodi, Italy); Matteo SUBERT (ASST Melegnano Martesana, Melzo Hospital, Milan, Italy); Paola TAGLIABUE (Fondazione IRCCS Ca' Granda Ospedale Maggiore Policlinico, Milan, Italy); Carmine TROIANO (ASST Crema, Maggiore Hospital, Crema, Italy); Roberto VALSECCHI (Moriggia Pelascini General Hospital, Gravedona, Como, Italy); Uberto VIOLA (San Pellegrino Hospital, Mantua Salus Group, Mantua, Italy); Giovanni VITALE (San Marco Polyclinic, Zingonia, Bergamo, Italy); Massimo ZAMBON (ASST Melegnano-Martesana, Hospital of Cernusco sul Naviglio, Italy); Alberto ZANGRILLO (IRCCS San Raffaele Hospital, Vita-Salute San Raffaele University, Milan, Italy); Elena ZOIA (ASST Fatebenefratelli Sacco, Luigi Sacco Hospital, University of Milan, Milan, Italy).

Authors' contributions.-All authors read and approved the final version of the manuscript.

Comment in: Arnal JM, Talmor D. Collective wisdom in a pandemic. Minerva Anestesiol 2020;86:1132-4. DOI: 10.23736/S03759393.20.15238-6.

History.-Manuscript accepted: September 15, 2020. - Manuscript revised: July 27, 2020. - Manuscript received: May 4, 2020. 